\title{
A Harmonic Elimination and Suppression Scheme for an Open-End Winding Induction Motor Drive
}

\author{
Krushna K. Mohapatra, Student Member, IEEE, K. Gopakumar, Senior Member, IEEE, \\ V. T. Somasekhar, Student Member, IEEE, and L. Umanand
}

\begin{abstract}
In this paper, a harmonic elimination and suppression scheme for a dual-inverter-fed open-end winding induction motor drive is presented. Two isolated dc-link sources with voltage ratio of approximately $1: 0.366$ are required for the present drive. These two isolated dc links feeding two inverters to drive the openend winding induction motor eliminate the triplen harmonic currents from the motor phase. The pulsewidth-modulation scheme proposed enables the cancellation of all the 5th- and 7th-order ( $6 n \pm 1$, where $n=1,3,5,7$, etc.) harmonic voltages and suppresses the 11th- and 13th-order harmonic voltage amplitudes in the motor phase voltage, in all modulation ranges. The next higher order harmonics present in the motor phase voltages are 23rd, 25th, 35th, 37th etc. ( $6 n \pm 1, n=4,6$, etc.). By using triangular carrier wave and proper modulating waves for each inverter, the open-end winding induction motor can be operated in the entire modulation range, eliminating all the $6 n \pm 1$ harmonics $(n=1,3,5,7$, etc.) coupled with 11th and 13th harmonic suppression. The proposed scheme also gives a smooth transition to the overmodulation region.
\end{abstract}

Index Terms-Harmonic elimination, harmonic suppression, open-end induction motor, pulsewidth-modulation (PWM) drive.

\section{INTRODUCTION}

$\mathbf{I}$ $\mathrm{N}$ ORDER to reduce inverter switching losses and limit the ripple currents in the motor phase multilevel inverters of the type three-level, five-level, etc., [1]-[3] are preferred to the conventional two-level inverter. However, this increase in number of levels enhances the power circuit complexities and in turn affects the cost of the system dearly. Another interesting and suitable topology called the open-end winding induction motor (IM) drive are presently being studied for high-power applications [4]-[7]. The neutral of the IM is disconnected in an open-end winding drive and two separate three-phase inverters feed the motor from both ends of the stator winding. The inverters are fed from dc-link sources of half the magnitude, when compared to the same in conventional two-level inverters [4]. In order to avoid the flow of triplen harmonic currents in the motor phase, isolated dc-link power sources or harmonic filters are required for these drives [4]-[6]. Similar to a conventional multilevel inverter, more voltage space phasor levels can be achieved by using asymmetric dc-link voltages for the two inverters [7]. In the present work, a technique to eliminate and suppress certain harmonics in an open-end winding induction motor drive is studied. There are

Manuscript received November 26, 2001; revised January 15, 2003. Abstract published on the Internet September 17, 2003.

The authors are with the Centre for Electronics Design and Technology, Indian Institute of Science, Bangalore 560012, India (e-mail: kgopa@cedt.iisc. ernet.in).

Digital Object Identifier 10.1109/TIE.2003.819670 well-established techniques to suppress and eliminate different harmonics in normal IM drives [8]. By using notches at suitable points in the square wave certain harmonics are eliminated from the output [8]. These schemes requires extensive off line computations to determine the notches for different speed ranges. One of the schemes uses staircase type modulating wave to suppress the harmonics [9]. The disadvantages of all those schemes are the need for lookup tables and large offline computation. This paper presents a unique and simple scheme for an open-end winding IM drive, where all the 5th- and 7th-order $(6 n \pm 1$, where $n=1,3,5,7$, etc.) harmonics are eliminated and the 11 thand 13th-order harmonics are suppressed to a significant extent for the entire modulation range. The other feature of the scheme is that speed control using triangle carrier is possible with low frequency harmonic elimination and suppression and without resorting to very high-frequency pulsewidth-modulation (PWM) switchings. A smooth transition to the overmodulation region is also possible from the proposed drive scheme.

\section{Power Circuit For the Drive Scheme}

In an open-end IM drive the neutral point of the induction motor is disconnected and two separate inverters feed the three-phase windings of the motor from both ends [4]. Fig. 1(a) shows the power circuit schematic of such a drive system. As shown in Fig. 1(a), inverter-1 and inverter-2 feed the motor from two isolated dc-link sources. The voltage ratio of the two dc-link sources is $1: 0.366$. In the present case the dc-link voltage of inverter-1 is $\mathrm{V}_{\mathrm{DC}}$ and the dc-link voltage ( $\mathrm{Vdc}$ ) of inverter- 2 is $0.366 \mathrm{~V}_{\mathrm{DC}}$.

Fig. 1(b) shows the voltage space vector positions of the individual inverters (inverter-1 and inverter-2). It can be noted that the magnitude of voltage space vector of inverter- 2 is $36.6 \%$ of that of inverter-1 [Fig. 1(b)]. Fig. 2(a) shows the resultant space vectors using only certain space vector combinations from inverter-1 and inverter-2. The voltage space vector amplitudes of inverter- 1 and inverter- 2 depends on the inverters dc-link voltages. To get a 12-sided voltage space vector combination, for the vector combinations $13^{\prime}, 15^{\prime}, 24^{\prime}, 26^{\prime}, 35^{\prime}, 31^{\prime}, 46^{\prime}, 42^{\prime}$, $51^{\prime}, 53^{\prime}, 62^{\prime}, 64^{\prime}$ [Fig. 2(a)], the switching vector magnitude of inverter- 2 should be 0.366 times that of inverter-1 [Fig. 2(b)]. This can be calculated from the geometry of Fig. 2(b). Since the switching vector magnitude of a two-level inverter is proportional to the value of its dc-link voltage, a dc-link voltage ratio of $1: 0.366$ between inverter- 1 and inverter- 2 is needed to realize a resultant 12-sided polygonal voltage space phasor location of Fig. 2(a). The set of certain space vector combinations of $13^{\prime}, 15^{\prime}, 24^{\prime}, 26^{\prime}, 35^{\prime}, 31^{\prime}, 46^{\prime}, 42^{\prime}, 51^{\prime}, 53^{\prime}, 62^{\prime}$, 


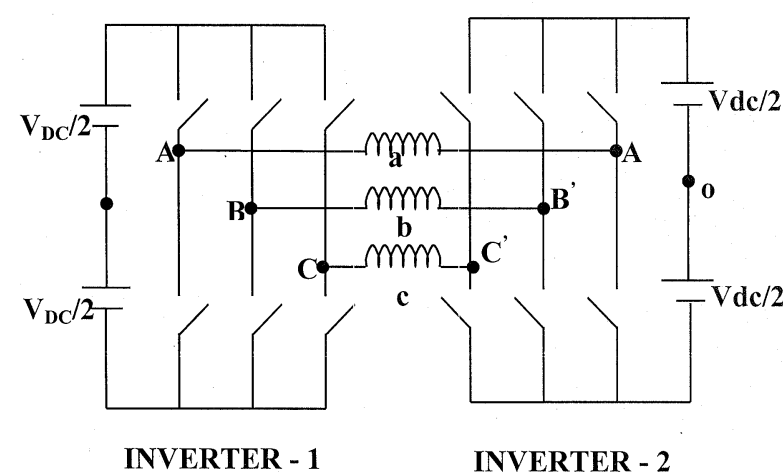

(a)

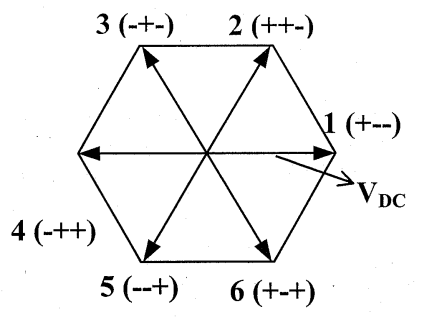

Vector diagram inverter -1 Vector magnitude $=V_{D C}$

Vector diagram inverter -2 Vector magnitude $=\mathrm{Vdc}$

(b)

Fig. 1. (a) Schematic of power circuit for the proposed scheme. $\mathrm{Vdc}=$ $0.366 \mathrm{~V}_{\mathrm{DC}}$. (b) Vector diagrams of individual inverters.

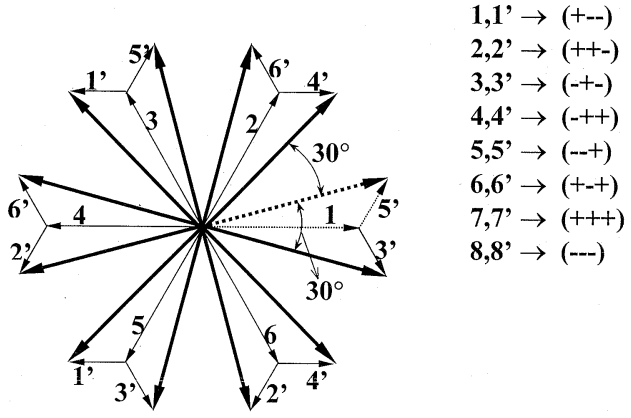

(a)

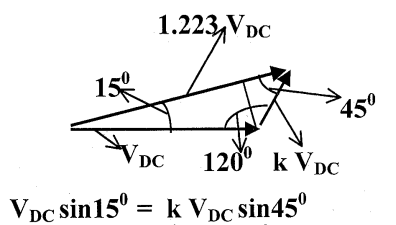

So $k=\sin 15^{\circ} / \sin 45^{\circ}=0.366$

(b)

Fig. 2. (a) Selected combinations of the vector positions from inverter-1 and inverter-2. (b) Calculation of dc-link voltage ratio (k) for both inverters.

$64^{\prime}$ [Fig. 2(a)] makes a 12-sided polygon at their vertices with a dc-link voltage ratio of $1: 0.366$ between the inverters. By using vector positions at the vertices of the 12-sided polygon (adjacent vectors are $30^{\circ}$ separate), appropriately for PWM operation, all the 5th- and 7th- $(6 n \pm 1, n=1,3,5$, etc. $)$-order harmonics can be cancelled from the motor phase voltage. This set of 12 space vectors can be divided into two sets, one consisting of vectors $13^{\prime}, 24^{\prime}, 35^{\prime}, 46^{\prime}, 51^{\prime}, 62^{\prime}$ and the other

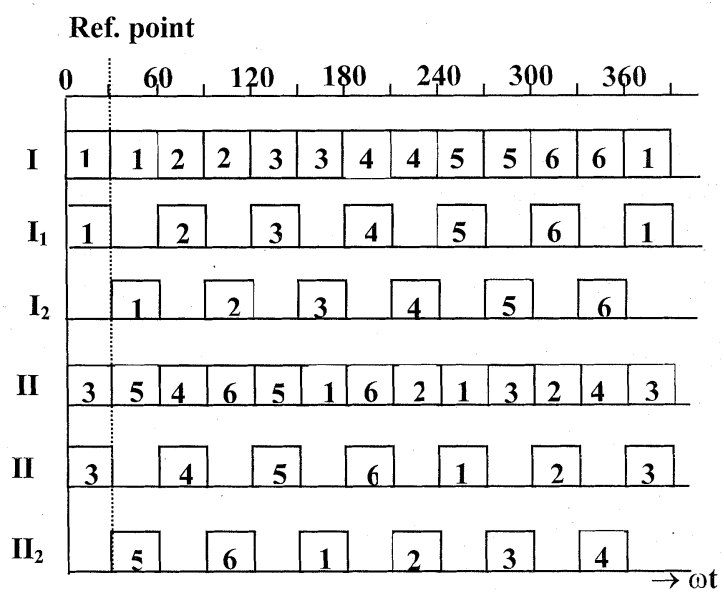

(a)

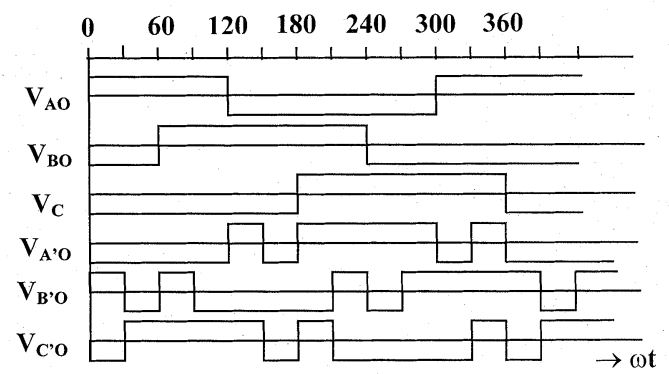

(b)

Fig. 3. Individual voltage space-vector switching pattern and its duration for inverter-1 and inverter-2 for a resultant 12-sided polygonal space vector switching. (b) Pole voltage $\left(\mathrm{V}_{\mathrm{AO}}, \mathrm{V}_{\mathrm{BO}}, \mathrm{V}_{\mathrm{CO}}\right)$ of inverter-1 and pole voltage

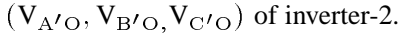

consisting of vectors $15^{\prime}, 26^{\prime}, 31^{\prime}, 42^{\prime}, 53^{\prime}, 64^{\prime}$, separated by $30^{\circ}$. Therefore, if these two sets of vectors are switched (clockwise direction) with a $30^{\circ}$ phase delay in time, the fundamental component of both these sets add up because the fundamental of the leading set of vectors move by $30^{\circ}$ clockwise in space when lagging set of vectors are switched. However, the 5th-order harmonics (negative-sequence components $6 n-1, n=1,3,5$, etc.) of the leading set of vectors move by $150^{\circ}$ anticlockwise in space when lagging set of vectors are switched, and comes exactly in opposition to the 5th harmonics of the lagging set of switching vectors and cancel each other. Hence, the 5th order harmonics $(6 n-1, n=1,3,5$, etc.) of both sets of vectors cancel each other. This is also true with the 7th-order harmonic components $(6 n+1, n=1,3,5$, etc.) produced by the leading set of vectors, which rotate by $210^{\circ}$ clockwise and comes in exact opposition to that of the lagging set and, hence, cancel each other. Thus, a $30^{\circ}$ vector disposition of switching vectors [Fig. 2(a)], cancels all the 5th- and 7th-order $(6 n \pm 1, n=13,5$, etc.) voltage harmonics from the motor phase.

\section{HARMONIC ANALYSIS FOR THE ( $6 n \pm 1, n=1,3,5$, ETC.)-ORDER HARMONIC ELIMINATION SCHEME}

The individual inverter voltage space vector switching and its duration for the two inverters are presented in Fig. 3(a). It can be noted from Fig. 3(a) that for inverter- 1 the $60^{\circ}$ duration of individual vectors from 1 to $6(I)$ are separated into $30^{\circ}$ intervals as 


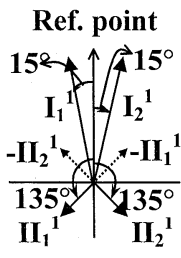

(a)

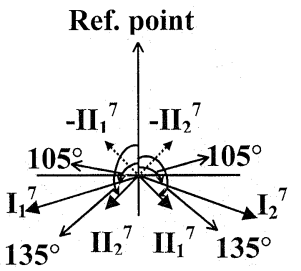

(c)

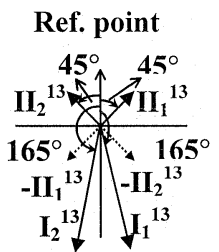

(e)

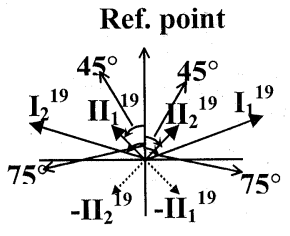

(g)

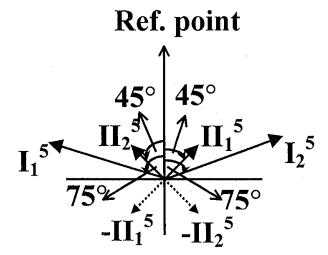

(b)

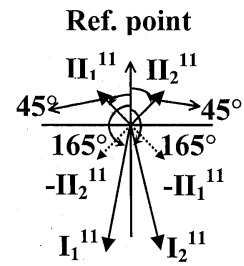

(d)

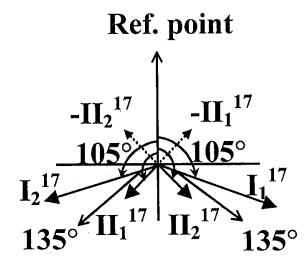

(f)

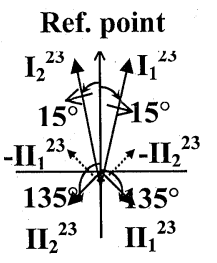

(h)

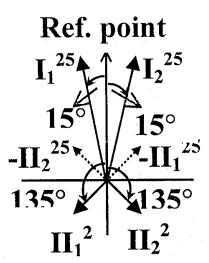

(i)

Fig. 4. Relative position of different harmonics of the motor phase from both inverter-1 and inverter-2. (a) Fundamental. (b) 5th harmonics. (c) 7th harmonics. (d) 11th harmonics. (e) 13th harmonics. (f) 17th harmonics. (g) 19th harmonics. (h) 23rd harmonics. (i) 25 th harmonics.

$I_{1}$ and $I_{2}$. The corresponding space vector switching pattern for inverter-2 ( $I I$ of Fig. 3(a) is separated into $30^{\circ}$ interval space vector switching pattern and are shown in Fig. 3(a) as $I I_{1}$ and $I I_{2}$. From Fig. 3(a) it can be seen that there is a $30^{\circ}$ phase difference between the two sequences (i.e., between the switching vector patterns $I_{1}$ and $I_{2}$ of Fig. 3(a). Similarly the switching vector pattern $I I_{1}$ leads by $120^{\circ}$ from $I_{1}$ [Fig. 3(a)] and the switching vector pattern $I I_{2}$ lags by $120^{\circ}$ from $I_{2}$ [Fig. 3(a)]. The corresponding pole voltage waveforms for the two inverters are presented in Fig. 3(b).

The phasor diagram of the fundamental and different harmonic components of switching vector patterns $I_{1}, I_{2}, I I_{1}$ and $I I_{2}$ of Fig. 3(a) are shown in Fig. 4. There is a phase separation of $30^{\circ}$ between the vectors $I_{1}^{1}$ and $I_{2}^{1}$ of Fig. 4(a). Fig. 4(a) also shows that the fundamental component $I I_{1}^{1}$ of the switching vector pattern $I I_{1}$ of Fig. 3(a) leads by $135^{\circ}$ from the reference point (i.e., vector $I I_{1}^{1}$ leads $I_{1}^{1}$ by $120^{\circ}$ [Fig. 4(a)] and fundamental component $I I_{2}^{1}$ of the switching vector pattern $I I_{2}$ of Fig. 3(a) lags by $135^{\circ}$ from the reference point (i.e., vector $I I_{2}^{1}$ lags $I_{2}^{1}$ by $120^{\circ}$ [Fig. 4(a)]. Fig. 4(b) shows the phasor diagram of the 5th harmonics. The 5th harmonic component $I_{1}^{5}$ of the switching vector pattern $I_{1}$ of Fig. 3(a) leads by $75^{\circ}\left(15^{\circ} \times 5\right)$ from the reference point [Fig. 4(b)] and 5th harmonic component $I_{2}^{5}$ of the switching vector pattern $I_{2}$ of Fig. 3(a) lags by $75^{\circ}$ $\left(15^{\circ} \times 5\right)$ from the reference point [Fig. 4(b)]. The 5th harmonic component $I I_{1}^{5}$ of the switching vector pattern $I I_{1}$ [Fig. 3(a)] lags by $45^{\circ}\left(135^{\circ} \times 5\right.$ lead $)$ from the reference point [Fig. 4(b)] and 5 th harmonic component $I I_{2}^{5}$ of the switching vector pattern $I I_{2}$ of Fig. 3(a) leads by $45^{\circ}\left(135^{\circ} \times 5\right.$ lag $)$ from the reference point [Fig. 4(b)], or, in other words, $I I_{1}^{5}$ leads by $240^{\circ}(120 \times 5$ $=600)$ from $I_{1}^{5}$ and $I I_{2}^{5}$ lags by $240^{\circ}(120 \times 5=600)$ from $I_{2}^{5}$ [Fig. 4(b)]. Table I gives the relative angular positions (Fig. 4), of the different harmonics phasors of the switching vector patterns of $I_{1}, I_{2}, I I_{1}$ and $I I_{2}$ of Fig. 3(a), with respect to the reference point. Because inverter-1 and inverter- 2 are feeding from opposite ends, the space vector of inverter- 2 should be subtracted from that of inverter-1 to get the resultant motor phase voltage vector. As shown in Fig. 4 and Table I it can be noted that all the $6 n \pm 1, n=0,2$, 4 , etc.-order harmonics of the pole voltage of inverter- 1 and inverter- 2 support each other, and all the $6 n \pm 1, n=1,3,5$, etc.-order harmonics of the pole voltages of both inverters (inverter-1 and inverter-2) oppose each other. Hence, by selecting the dc-link voltages of both inverters in proper ratio (i.e., the dc-link voltage of inverter- $1\left(\mathrm{~V}_{\mathrm{Dc}}\right)$ to the dc-link voltage of inverter-2 (Vdc) equal to $1: 0.366)$ all the $6 n \pm 1, n=1,3,5$, etc.-order harmonics can be cancelled from the motor phase voltage. The calculation of amplitude of different harmonics are given below.

A. Amplitude of Fundamental and all the $24 n+1, n=1,2$, etc., Harmonics (1st, 25th, 49th, etc.)

The dc-link voltage of inverter-2,

$$
\mathrm{Vdc}=0.366 \mathrm{~V}_{\mathrm{DC}} \text {. }
$$

Now, the fundamental component $\left[I I_{1}^{1}\right.$ and $I I_{2}^{1}$ of Fig. 4(a)] of sequence $I I_{1}$ and $I I_{2}$ of Fig. 3(a), can be written in relation to that of sequence [Fig. 3(a)] $I_{1}$ and $I_{2}$ as

$$
I I_{1}^{1}=0.366 I_{1}^{1} \quad I I_{2}^{1}=0.366 I_{2}^{1}
$$

where $I_{1}^{1}$ and $I_{2}^{1}$ [Fig. 4(a)] are the fundamental components of pole voltage of inverter- 1 for sequences $I_{1}$ and $I_{2}$ [Fig. 3(a)]. The combination of vector patterns $I_{1}$ and $I_{2}$ of Fig. 3(a) generates square-wave pole voltages [Fig. 3(b)] with the fundamental component $E_{1}^{1}$ (square wave) is [Fig. 4(a)]

$$
E_{1}^{1}=0.637 \mathrm{~V}_{\mathrm{DC}}=2 I_{1}^{1} \cos 15^{\circ} .
$$

Hence, total fundamental voltage $\left(I^{1}\right)$ for the motor phase (resultant of both the inverters) voltage is

$$
I^{1}=2 I_{1}^{1} \cos 15^{\circ}+2 I I_{1}^{1} \cos 45^{\circ}=E_{1}^{1}+E_{2}^{1} .
$$


TABLE I

Phasor Positions of Different Harmonics of Switching Vector Patterns of the two InVerters

\begin{tabular}{|c|c|c|c|c|c|c|c|c|}
\hline $\begin{array}{l}\text { Switching } \\
\text { vector } \\
\text { patterns } \\
\text { (Fig.3a) }\end{array}$ & \multicolumn{2}{|c|}{$\begin{array}{l}\text { Fundamental } \\
\text { and } \\
(24 \mathrm{n}+1 \text {, } \\
\mathrm{n}=1,2 . .) \\
\text { harmonics w.r.t. } \\
\text { ref point }\end{array}$} & \multicolumn{2}{|c|}{$\begin{array}{l}5^{\text {th }} \text {-harmonic } \\
\text { and } \\
(24 n+5, \\
n=1,2, \ldots . .) \\
\text { harmonics w.r.t. } \\
\text { ref point }\end{array}$} & $\begin{array}{l}7^{\text {th }} \text {-harmonic } \\
\text { and } \\
(24 \mathrm{n}+7, \\
\mathrm{n}=1,2, \ldots . .) \\
\text { harmonics w.r.t. } \\
\text { ref point }\end{array}$ & \multicolumn{2}{|c|}{$\begin{array}{l}11^{\text {th }} \text {-harmonic } \\
\text { and } \\
(24 \mathrm{n}+11, \\
\mathrm{n}=1,2, \ldots . .) \\
\text { harmonics w.r.t. } \\
\text { ref point }\end{array}$} & $\begin{array}{l}13^{\text {th }} \text {-harmonic } \\
\text { and } \\
(24 \mathrm{n}+13, \\
\mathrm{n}=1,2, \ldots . .) \\
\text { harmonics w.r.t. } \\
\text { ref point }\end{array}$ \\
\hline$I_{1}$ & \multicolumn{2}{|c|}{$15^{\circ}$ lead } & \multicolumn{2}{|l|}{$\begin{array}{l}\left(15^{\circ} \times 5\right) \text { lead } \\
=75^{\circ} \mathrm{lead}\end{array}$} & $\begin{array}{l}\left(15^{\circ} \times 7\right) \text { lead } \\
=105^{\circ} \text { lead }\end{array}$ & \multicolumn{2}{|c|}{$\begin{array}{l}\left(15^{\circ} \times 11\right) \text { lead } \\
=165^{\circ} \text { lead }\end{array}$} & $\begin{array}{l}\left(15^{\circ} \times 13\right) \text { lead } \\
=105^{\circ} \mathrm{lag}\end{array}$ \\
\hline $\mathrm{I}_{2}$ & \multicolumn{2}{|c|}{$15^{\circ} \mathrm{lag}$} & \multicolumn{2}{|l|}{$\begin{array}{l}\left(15^{\circ} \times 5\right) \mathrm{lag} \\
=75^{\circ} \mathrm{lag}\end{array}$} & $\begin{array}{l}\left(15^{\circ} \times 7\right) \mathrm{lag} \\
=105^{\circ} \mathrm{lag}\end{array}$ & \multicolumn{2}{|c|}{$\begin{array}{l}\left(15^{\circ} \times 11\right) \text { lag } \\
=165^{\circ} \mathrm{lag}\end{array}$} & $\begin{array}{l}\left(15^{\circ} \times 13\right) \mathrm{lag} \\
=105^{\circ} \mathrm{lead}\end{array}$ \\
\hline $\mathrm{II}_{1}$ & \multicolumn{2}{|c|}{$135^{\circ}$ lead } & \multicolumn{2}{|l|}{$\begin{array}{l}\left(135^{\circ} \times 5\right) \text { lead } \\
=45^{\circ} \text { lag }\end{array}$} & $\begin{array}{l}\left(135^{\circ} \times 7\right) \text { lead } \\
=135^{\circ} \mathrm{lag}\end{array}$ & \multicolumn{2}{|c|}{$\begin{array}{l}\left(135^{\circ} \times 11\right) \text { lead } \\
=45^{\circ} \text { lead }\end{array}$} & $\begin{array}{l}\left(135^{\circ} \times 13\right) \text { lead } \\
=45^{\circ} \mathrm{lag}\end{array}$ \\
\hline $\mathrm{II}_{2}$ & \multicolumn{2}{|c|}{$135^{\circ} \mathrm{lag}$} & \multicolumn{2}{|l|}{$\begin{array}{l}\left(135^{\circ} \times 5\right) \text { lag } \\
=45^{\circ} \text { lead }\end{array}$} & $\begin{array}{l}\left(135^{\circ} \times 7\right) \text { lag } \\
=135^{\circ} \text { lead }\end{array}$ & \multicolumn{2}{|c|}{$\begin{array}{l}\left(135^{\circ} \times 11\right) \text { lag } \\
=45^{\circ} \mathrm{lag}\end{array}$} & $\begin{array}{l}\left(135^{\circ} \times 5\right) \mathrm{lag} \\
=45^{\circ} \text { lead }\end{array}$ \\
\hline \multicolumn{2}{|c|}{$\begin{array}{l}\text { Switching } \\
\text { vector patterns } \\
\text { (Fig.3a) }\end{array}$} & \multicolumn{2}{|c|}{$\begin{array}{l}17^{\text {th }} \text {-harmonic and } \\
(24 n+17, n=1,2, \ldots \ldots) \\
\text { harmonic w.r.t. ref point }\end{array}$} & \multicolumn{3}{|c|}{$\begin{array}{l}19^{\text {th }} \text {-harmonic and } \\
(24 n+19, n=1,2, \ldots . .) \\
\text { harmonics w.r.t. ref point }\end{array}$} & \multicolumn{2}{|c|}{$\begin{array}{l}23^{\text {rd }} \text {-harmonic and } \\
(24 \mathrm{n}+23, \mathrm{n}=1,2, \ldots \ldots) \\
\text { harmonics w.r.t. ref point }\end{array}$} \\
\hline \multicolumn{2}{|l|}{$\mathrm{I}_{1}$} & \multicolumn{2}{|c|}{$\begin{array}{l}\left(15^{\circ} \times 17\right) \text { lead } \\
=105^{\circ} \mathrm{lag}\end{array}$} & \multicolumn{3}{|c|}{$\begin{array}{l}\left(15^{\circ} \times 19\right) \text { lead } \\
=75^{\circ} \mathrm{lag}\end{array}$} & \multicolumn{2}{|c|}{$\begin{array}{l}\left(15^{\circ} \times 23\right) \text { lead } \\
=15^{\circ} \mathrm{lag}\end{array}$} \\
\hline \multicolumn{2}{|l|}{$\mathrm{I}_{2}$} & \multicolumn{2}{|c|}{$\begin{array}{l}\left(15^{\circ} \times 17\right) \mathrm{lag} \\
=105^{\circ} \mathrm{lead}\end{array}$} & \multicolumn{3}{|c|}{$\begin{array}{l}\left(15^{\circ} \times 19\right) \mathrm{lag} \\
=75^{\circ} \text { lead }\end{array}$} & \multicolumn{2}{|c|}{$\begin{array}{l}\left(15^{\circ} \times 23\right) \text { lag } \\
=15^{\circ} \text { lead }\end{array}$} \\
\hline \multicolumn{2}{|l|}{$\mathrm{II}_{1}$} & \multicolumn{2}{|c|}{$\begin{array}{l}\left(135^{\circ} \times 17\right) \text { lead } \\
=135^{\circ} \text { lead }\end{array}$} & \multicolumn{3}{|c|}{$\begin{array}{l}\left(135^{\circ} \times 19\right) \text { lead } \\
=45^{\circ} \text { lead }\end{array}$} & \multicolumn{2}{|c|}{$\begin{array}{l}\left(135^{\circ} \times 23\right) \text { lead } \\
=135^{\circ} \mathrm{lag}\end{array}$} \\
\hline \multicolumn{2}{|l|}{$\mathrm{II}_{2}$} & \multicolumn{2}{|c|}{$\begin{array}{l}\left(135^{\circ} \times 17\right) \mathrm{lag} \\
=135^{\circ} \mathrm{lag}\end{array}$} & \multicolumn{3}{|c|}{$\begin{array}{l}\left(135^{\circ} \times 19\right) \mathrm{lag} \\
=45^{\circ} \mathrm{lag}\end{array}$} & \multicolumn{2}{|c|}{$\begin{array}{l}\left(135^{\circ} \times 23\right) \text { lag } \\
=135^{\circ} \text { lead }\end{array}$} \\
\hline
\end{tabular}

Substituting (2) and (3) in (4),

$$
I^{1}=2.499 I_{1}^{1}=\frac{2.499\left(0.637 \mathrm{~V}_{\mathrm{DC}}\right)}{\left(2 \cos 15^{\circ}\right)}=0.807 \mathrm{~V}_{\mathrm{DC}} \text {. }
$$

Similarly, all the $24 n+1, n=1,2$, etc., harmonics amplitudes in motor phase voltage can be calculated and is found to be equal to $0.807 \mathrm{~V}_{\mathrm{Dc}} /(24 n+1), n=1,2$, etc.

B. Amplitude of all the $24 n+5, n=0,1,2$, etc., Harmonics (5th, 29th, 53rd, etc.)

Total 5th harmonic amplitude of the motor phase voltage can be calculated from Fig. 4(b) (Table I)

$$
\begin{aligned}
I^{5} & =2 I_{1}^{5} \cos 75^{\circ}-2 I I_{1}^{5} \cos 45^{\circ} \\
& =2\left(I_{1}^{5} \cos 75^{\circ}-0.366 I_{1}^{5} \cos 45^{\circ}\right)=0 .
\end{aligned}
$$

Similarly, using the phasor diagram of Fig. 4 all the $24 n+5$, $n=1,2$, etc., harmonics amplitudes in motor phase voltage can be calculated and are found to be equal to zero.

C. Amplitude of all the $24 n+7, n=0,1,2$, etc., Harmonics (7th, 31st, 55th, etc.)

Total 7th harmonic amplitude (from both the inverters) can be calculated from Fig. 4(c) (Table I)

$$
I^{7}=-2 I_{1}^{7} \cos 75^{\circ}-2 I I_{1}^{7} \cos 45^{\circ}=0
$$

and all the $24 n+7, n=1,2$, etc., harmonics amplitudes in motor phase voltage can be calculated in a similar way and are found to be equal to zero.
D. Amplitude of all the $24 n+11, n=0,1,2$, etc., Harmonics (11th, 35th, 59th, etc.)

Total 11th harmonic amplitude (motor phase voltage) from Fig. 4(d) and Table $I$ is

$$
\begin{aligned}
I^{11} & =-2 I_{1}^{11} \cos 15^{\circ}-2 I I_{1}^{11} \cos 15^{\circ} \\
& =2 I_{1}^{11}\left(\cos 15^{\circ}+0.366\right) \cos 45^{\circ} \\
& =-2.449\left(I_{1}^{11}\right) .
\end{aligned}
$$

The amplitude of the 11th harmonic component of the square wave [combination of vector pattern $I_{1}$ and $I_{2}$ of Fig. 3(a)] is $(0.637 / 11)$

$$
\mathrm{V}_{\mathrm{DC}}=-2 I_{1}^{11} \cos 165^{\circ}
$$

From (8) and (9) the total 11th harmonic for the motor phase voltage [for the switching pattern of Fig. 3(a)] is

$$
I^{11}=\frac{0.807 \mathrm{~V}_{\mathrm{DC}}}{11}=0.073 \mathrm{~V}_{\mathrm{DC}}
$$

and all the $24 n+11, n=1,2$, etc., harmonics amplitudes in motor phase voltage can be calculated to be equal to $0.807 \mathrm{~V}_{\mathrm{Dc}} /(24 n+11), n=1,2$, etc. In a similar way amplitudes of all the other harmonics in the motor phase voltage can be calculated for the inverters switching pattern of Fig. 3(a) (Fig. 4 and Table I), and the calculated values are given in Table II.

It can be noted that all the $6 n \pm 1, n=1,3,5$, etc.-order harmonics in the motor phase voltage are totally absent and all the $6 n \pm 1, n=2,4,6$, etc.-order harmonic amplitudes are 1.267 
TABLE II

HARMONIC AMPLiTUdES OF Motor Phase Voltage

\begin{tabular}{|c|c|}
\hline Order of harmonics in phase voltage & Amplitude of the harmonic in phase voltage \\
\hline $24 \mathrm{n}+1, \mathrm{n}=0,1,2$ etc. harmonics $\left(1^{\mathrm{st}}, 25^{\text {th }}, 49^{\text {th }} ..\right)$ & $0.807 \mathrm{~V}_{\mathrm{DC}} /(24 \mathrm{n}+1), \mathrm{n}=0,1,2$ etc. \\
\hline $24 n+5, n=0,1,2$ etc. harmonics $\left(5^{\text {th }}, 29^{\text {th }}, 53^{\text {rd }}.\right)$ & 0 \\
\hline $24 \mathrm{n}+7, \mathrm{n}=0,1,2$ etc. harmonics $\left(7^{\text {th }}, 31^{\text {st }}, 55^{\text {th }}.\right)$ & 0 \\
\hline $24 \mathrm{n}+11, \mathrm{n}=0,1,2$ etc. harmonics $\left(11^{\text {th }}, 35^{\text {th }}, 59^{\text {th }} ..\right)$ & $0.807 V_{D C} /(24 n+11), n=0,1,2$ etc \\
\hline $24 n+13, n=0,1,2$ etc. harmonics $\left(13^{\text {th }}, 37^{\text {th }}, 61^{\text {st }} ..\right)$ & $0.807 V_{D C} /(24 n+13), n=0,1,2$ etc. \\
\hline $24 \mathrm{n}+17, \mathrm{n}=0,1,2$ etc. harmonics $\left(17^{\text {th }}, 41^{\text {st }}, 65^{\text {th }}, \ldots\right)$ & 0 \\
\hline $24 n+19, \quad n=0,1,2$ etc. harmonics $\left(19^{\text {th }}, 43^{\text {rd }}, 67^{\text {th }}, \ldots\right)$ & 0 \\
\hline $24 n+23, n=0,1,2$ etc. harmonics $\left(23^{\text {rd }}, 47^{\text {th }}, 71^{\text {st }}, \ldots\right)$ & $0.807 V_{D C} /(24 n+23), n=0,1,2$ etc. \\
\hline
\end{tabular}
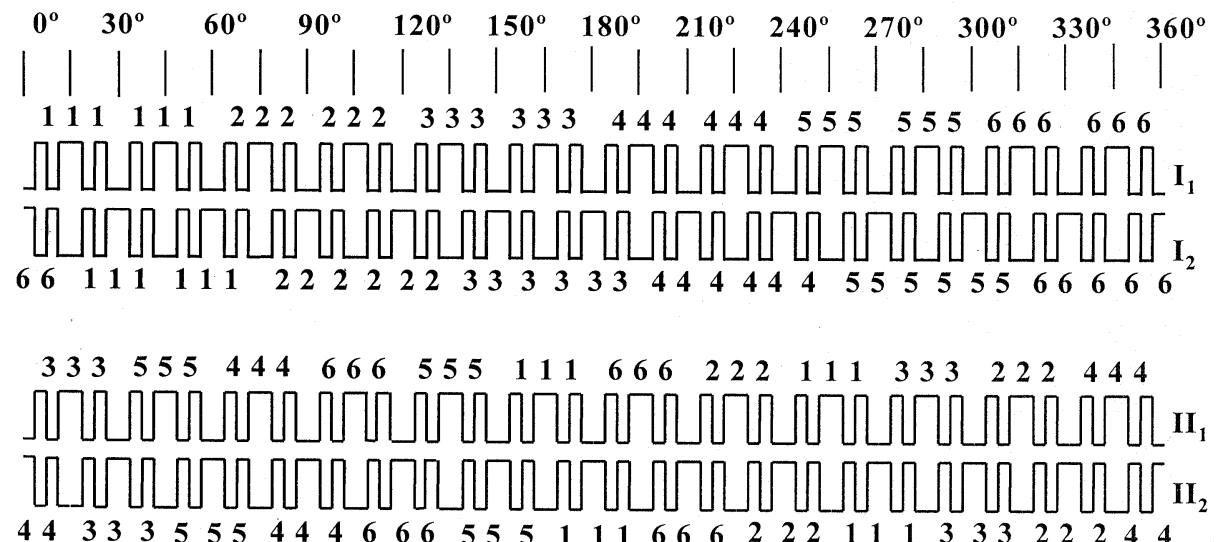

(a)

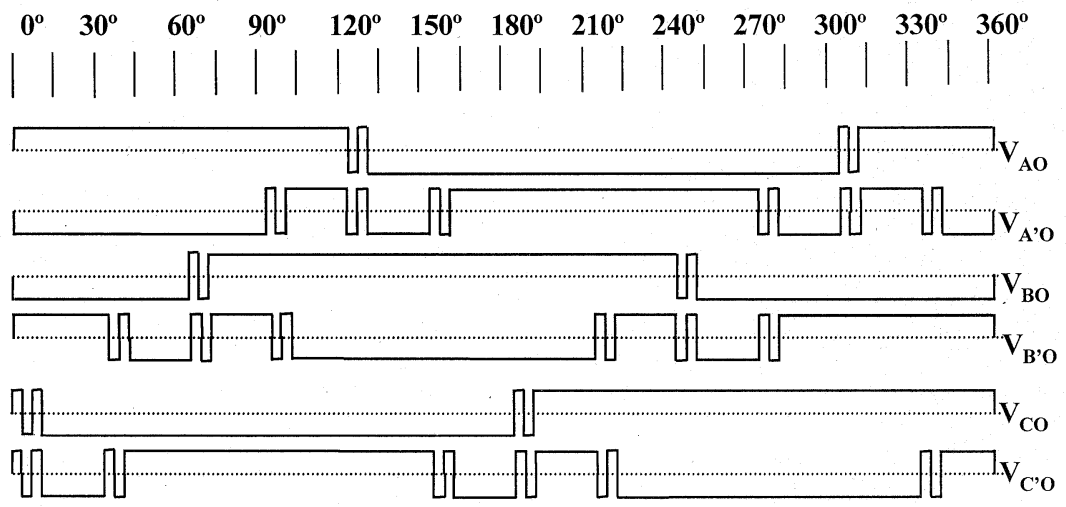

(b)

Fig. 5. (a) Inverter-1 vector switching patterns $\left(I_{1}\right.$ and $\left.I_{2}\right)$ and Inverter-2 vector switching patterns $\left(I I_{1}\right.$ and $\left.I I_{2}\right)$ for the scheme of 11 th and 13th harmonic suppression with $15^{\circ}$ phase shift. (b) Pole voltage waveforms for Inverter-1 and Inverter-2 with the inverter switching patterns of (a) for the scheme of 11 th and 13th harmonic suppression with $15^{\circ}$ phase shift.

times (0.807/0.637) amplitude of the same order harmonic of a conventional inverter with square-wave pole voltage waveform with a dc-link voltage of $\mathrm{V}_{\mathrm{DC}}$.

\section{SUPPRESSION OF 11TH- AND 13TH-ORDER HARMONICS}

For an open-end winding drive with two inverters of dc-link voltage ratio of $(1: 0.366)$ all the $(6 n \pm 1, n=1,3,5$, etc.) harmonics get cancelled for a switching pattern shown in Fig. 3(a). In Fig. 3(a) the switching pattern of inverter-1 is separated into $I_{1}$ and $I_{2}$ (with an angular difference of $30^{\circ}$ ), and the switching pattern of inverter- 2 is separated into $I I_{1}$ and $I I_{2}$ (with an angular difference of $90^{\circ}$ between them). Keeping the same symmetry in switching pattern [Fig. 3(a)], of both the inverters, the 11th- and 13th-order harmonics can be suppressed in the individual inverters by adding additional notches in the individual inverter pole voltages. For the new pole voltage waveforms [Fig. 5(b)] the individual inverter vector switching pattern $I_{1}$ and $I_{2}$ of inverter-1, and $I I_{1}$ and $I I_{2}$ of inverter-2 are presented in Fig. 5(a). The vector switching pattern $I_{1}$ again consists of two similar patterns separated by $30^{\circ}$ and the pattern $I_{2}$ of inverter- 1 is similar to the switching pattern $I_{1}$, but delayed by $15^{\circ}$. This $15^{\circ}$ separation is responsible for suppression of 11th and 13th harmonics in the inverter-1 pole voltage waveform. The corresponding vector switching pattern $I I_{1}$ and $I I_{2}$ of inverter-2 are also shown in Fig. 5(a). The leading 


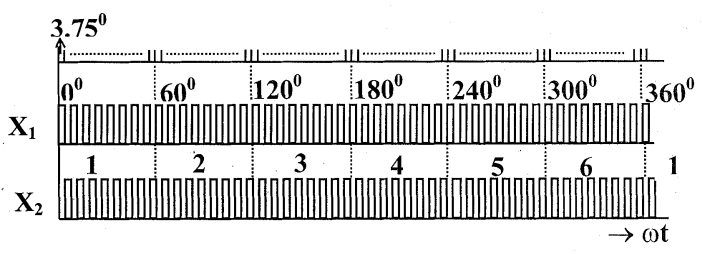

(a)

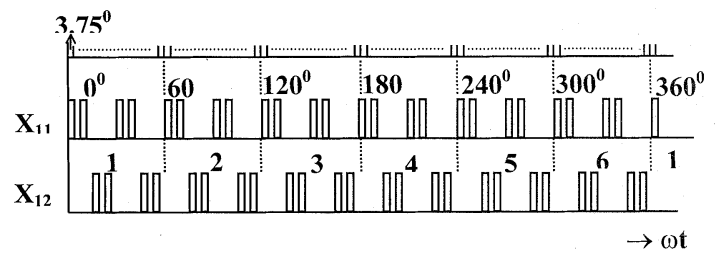

(c)

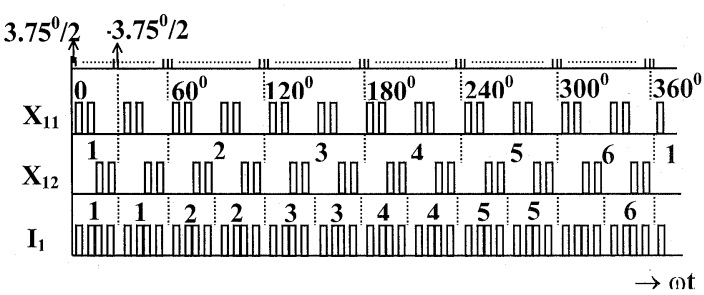

(e)

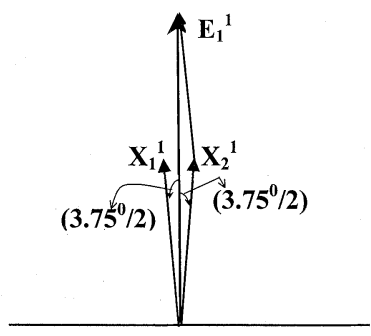

(b)

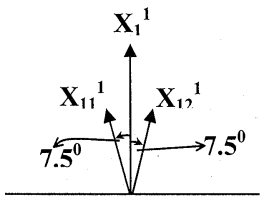

(d)

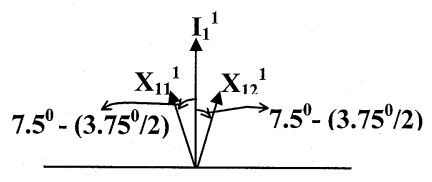

(f)

Fig. 6. Switching vector duration for six-step (Fig. 5) is divided into two switching vector patterns $X_{1}$ and $X_{2}$ with phase separation of $3.75^{\circ}$. (b) Fundamental component of the square wave is decomposed into $X_{1}^{1}$ and $X_{2}^{1}$ separated by $3.75^{\circ}$. (c) Inverter switching vector pattern $X_{1}$ decomposed into patterns $X_{11}$ and $X_{12}$, respectively. (d) $X_{1}^{1}$, fundamental vector of switching pattern $X_{1}$ is decomposed into $X_{11}^{1}$ (fundamental vector of vector pattern $X_{11}$ ) and $X_{12}^{1}$ (fundamental vector of vector pattern $X_{12}$ ). (e) Resultant switching vector pattern $\left(I_{1}\right)$ is obtained from $X_{11}$ (shifted by $3.75^{\circ} / 2$ ) and $X_{12}$ (shifted by $-3.75^{\circ} / 2$ ). (f) Relative position of fundamental component for the inverter switching pattern of (e).

inverter vector switching pattern (1-6) of $I_{1}$ of inverter-1 is lagging by $120^{\circ}$ from the corresponding switching (same time instants) vector pattern of $I I_{1}$ of inverter-2. The lagging inverter vector switching pattern (1 to 6$)$ of $I_{1}$ of inverter-1 is leading by $120^{\circ}$ from the corresponding switching vector pattern of $I I_{1}$ of inverter-2. Similar phase shift between vector switching pattern $I_{2}$ of inverter- 1 and $I I_{2}$ of inverter- 2 can be seen from Fig. 5(a). This $120^{\circ}$ phase shift between switching patterns of inverter-1 and inverter-2 [Fig. 3(a) and with a dc link voltage ratio $1: 0.366$ ] will ensure the cancellation of all the $6 n \pm 1, n=1,3,5$, etc.-order harmonics as explained previously (Section III). For inverter-2 patterns $I I_{1}$ and $I I_{2}$ are also $15^{\circ}$ separated [Fig. 5(a)], ensuring the suppression of 11thand 13th-order harmonics from the inverter-2 pole voltage. Fig. 5(b) shows the resultant pole voltages for the inverters for suppressing the 11th and 13th harmonics.

The procedure to obtain the switching vector patterns shown in Fig. 5(a) and their harmonic contents are presented using Fig. 6(a)-(f). In Fig. 6(a) the inverter vector switching duration for a six-step mode operation (vector 1-6 of switching vector pattern $I$ of Fig. 3(a) is split into two patterns $X_{1}$ and $X_{2}$ with a $3.75^{\circ}$ duration. The addition of $X_{1}$ and $X_{2}$ will produce the inverter vector switching pattern $I$ (six-step operation) of Fig. 3(a). The fundamental components of individual vector switching patterns, $\left(X_{1}^{1}\right.$ and $\left.X_{2}^{1}\right)$ are shown in Fig. 6(b) which are also separated by $3.75^{\circ}$. The vector addition of these two components $\left(X_{1}^{1}\right.$ and $\left.X_{2}^{1}\right)$ will give the resultant fundamental component which is equal to that of a six-step mode operation. Now, to generate the inverter switching pattern $I_{1}$ and $I_{2}$ of Fig. 5(a), the $X_{1}$ or $X_{2}$ component of Fig. 6(a) can again be separated into two patterns $X_{11}$ and $X_{12}$ which are $15^{\circ}$ separated as shown in Fig. 6(c). Fig. 6(d) shows the phasor diagram for the fundamental components of the inverter switching vector pattern of Fig. 6(c). Fig. 6(e) shows the generation of inverter switching vector pattern of $I_{1}$ of Fig. 5(a) by proper phase shifting of $X_{11}$ and $X_{12}\left(X_{11}\right.$ shifted right by $3.75^{\circ} / 2$ and $X_{12}$ shifted left by $3.75^{\circ} / 2$ ) of Fig. 6(c). Fig. 6(f) shows the relative position of fundamental components of the inverter switching pattern of Fig. 6(e). From Fig. 6(a), it can be noted that addition of inverter switching pattern $X_{1}$ and $X_{2}$ will result in square-wave switching for inverter pole voltage. Hence, the fundamental component $E_{1}^{1}$ (six-step mode) of Fig. 6(b) is

$$
E_{I}^{1}=0.637 \mathrm{~V}_{\mathrm{DC}} \text { and } X_{I}^{1}=\left(\frac{E_{I}^{1}}{2 \cos 1.875^{\circ}}\right) .
$$

With reference to Fig. 6(d),

$$
X_{I I}^{1}=\left(\frac{X_{I}^{1}}{2 \cos 7.5^{\circ}}\right) \frac{E_{I}^{1}}{\left(2 \cos 7.5^{\circ}\right) \times\left(2 \cos 1.875^{\circ}\right)} .
$$

Now from Fig. 6(f),

$$
\begin{aligned}
I_{I}^{1} & =X_{I I}^{1} \times 2 \cos \left(7.5^{\circ}-1.875^{\circ}\right) \\
& =\frac{E_{I}^{1} \times\left(2 \cos \left(7.5^{\circ}-1.875^{\circ}\right)\right.}{\left(2 \cos 7.5^{\circ}\right) \times\left(2 \cos 1.875^{\circ}\right)} .
\end{aligned}
$$


Switching vector patterns $I_{1}$ and $I_{2}$ of Fig. 5(a) for inverter-1 are similar to switching vector pattern $I_{1}$ of Fig. 6(e) and are $15^{\circ}$ separated. Therefore, the fundamental vectors corresponding to these switching vector patterns are also $15^{\circ}$ separated. The resultant fundamental vector $V_{I}^{1}$ of inverter-1 [for the inverter switching sequence Fig. 5(b)] can be obtained from (14)

$$
\begin{aligned}
V_{I}^{1} & =\frac{E_{I}^{1} \times\left(2 \cos \left(7.5^{\circ}-1.875^{\circ}\right) \times\left(2 \cos 7.5^{\circ}\right)\right.}{\left(2 \cos 7.5^{\circ}\right) \times\left(2 \cos 1.875^{\circ}\right)} \\
& =0.637 \mathrm{~V}_{\mathrm{DC}} \times 0.9957
\end{aligned}
$$

where $0.637 \mathrm{~V}_{\mathrm{Dc}}$ is the fundamental component of the vector switching pattern of $I$ of Fig. 3(a) (six-step operation). Similarly, the 11th harmonic vector $V_{I}^{11}$ of inverter- 1 can also be written as (15), shown at the bottom of the page, and the 13th harmonic vector $V_{I}^{13}$ of inverter-1 is equal to (16), shown at the bottom of the page.

A similar approach can be used for the switching vector patterns $I I_{1}$ and $I I_{2}$ of Fig. 5(a) for inverter-2, and the fundamental vector $V_{I I}^{1}$ of inverter-2 is obtained from the fundamental components of the switching patterns $I I_{1}$ and $I I_{2}$ of Fig. 5(a). From Fig. 5(a) it can be noted that the switching patterns for inverter- 1 and inverter- 2 are similar and also the switching vector sequences follow the pattern of Fig. 3(a). Therefore,

$$
\begin{aligned}
V_{I I}^{1} & =\frac{E_{2}^{1} \times\left(2 \cos \left(7.5^{\circ}-1.875^{\circ}\right) \times\left(2 \cos 7.5^{\circ}\right)\right.}{\left(2 \cos 7.5^{\circ}\right) \times\left(2 \cos 1.875^{\circ}\right)} \\
& =E_{2}^{1} \times 0.9957
\end{aligned}
$$

where $E_{2}^{1}$ is the fundamental component of the vector pattern of $I I$ of Fig. 3(a). Referring to (2), (3), and (4),

$$
\begin{aligned}
E_{2}^{1} & =2 I I_{1}^{1} \cos 45^{\circ} \\
& =2 \times \frac{0.366 \times\left(0.637 \mathrm{~V}_{\mathrm{DC}}\right)}{2 \cos 15^{\circ}} \times \cos 45^{\circ} \\
& =0.1706 \mathrm{~V}_{\mathrm{DC}} .
\end{aligned}
$$

Similarly, the 11th-order harmonic vector $V_{I I}^{11}$ of inverter-2 is obtained from the 11th-order harmonic components of the switching patterns $I I_{1}$ and $I I_{2}$ of Fig. 5(a) and is equal to (19), shown at the bottom of the page, where $E_{2}^{11}$ is the 11th-order harmonic component of the vector pattern of $I I$ of Fig. 3(a) and is equal to $0.1706 \mathrm{~V}_{\mathrm{DC}} / 11$, and the 13 th harmonic vector $V_{I I}^{13}$ of inverter-2 is obtained from the 13th-order harmonic components of the switching patterns $I I_{1}$ and $I I_{2}$ of Fig. 5(a) and is equal to (20), shown at the bottom of the page, where $E_{2}^{13}$ is the 13th harmonic component of the vector pattern of $I I$ of Fig. 3(a) and is equal to $0.1706 \mathrm{~V} \_D C / 13$. Therefore, by adding (14) and (17) the total fundamental of the motor phase voltage from inverter-1 and inverter-2 for the inverter switching pattern of Fig. 5(a) is

$$
\begin{aligned}
V^{1} & =\left(E_{1}^{1}+E_{2}^{1}\right) \times 0.9957 \\
& =\left(0.637 \mathrm{~V}_{\mathrm{DC}}+0.1706 \mathrm{~V}_{\mathrm{DC}}\right) \times 0.9957 \\
& =0.807 \mathrm{~V}_{\mathrm{DC}} \times 0.9957
\end{aligned}
$$

Similarly, the 11th-order harmonic of the motor phase voltage is

$$
\begin{aligned}
V^{11} & =\left(E_{1}^{11}+E_{2}^{11}\right) \times 0.50 \\
& =\left(\frac{0.1706 \mathrm{~V}_{\mathrm{DC}}}{11}+\frac{0.637 \mathrm{~V}_{\mathrm{DC}}}{11}\right) \times 0.56 \\
& =0.073 \mathrm{~V}_{\mathrm{DC}} \times 0.50 .
\end{aligned}
$$

The total 13th-order harmonic of the motor phase voltage is

$$
\begin{aligned}
V^{13} & =\left(E_{1}^{13}+E_{2}^{13}\right) \times 0.3186 \\
& =\left\{\frac{0.1706 \mathrm{~V}_{\mathrm{DC}}}{13}+\frac{0.637 \mathrm{~V}_{\mathrm{DC}}}{13}\right\} \times 0.3186 \\
& =0.062 \mathrm{~V}_{\mathrm{DC}} \times 0.3186 .
\end{aligned}
$$

Equations (21)-(23) show that the resultant motor phase voltage fundamental is reduced to $99.57 \%$, 11th harmonic is reduced to $50 \%$, and 13th harmonic is reduced to $31.86 \%$ for the new

$$
V_{I}^{11}=\frac{E_{I}^{11} \times\left\{2 \cos \left(11 \times 7.5^{\circ}-11 \times 1.875^{\circ}\right)\right\} \times\left\{2 \cos \left(11 \times 7.5^{\circ}\right)\right\}}{\left\{2 \cos \left(11 \times 7.5^{\circ}\right)\right\} \times\left\{2 \cos \left(11 \times 1.875^{\circ}\right)\right\}}=E_{I}^{11} \times 0.50
$$

$$
V_{I}^{13}=\frac{E_{I}^{13} \times\left\{2 \cos \left(13 \times 7.5^{\circ}-13 \times 1.875^{\circ}\right)\right\} \times\left\{2 \cos \left(13 \times 7.5^{\circ}\right)\right\}}{\left\{2 \cos \left(13 \times 7.5^{\circ}\right)\right\} \times\left\{2 \cos \left(13 \times 1.875^{\circ}\right)\right\}}=\frac{0.637 V_{D C}}{13} \times 0.3186
$$

$$
V_{I I}^{11}=\frac{E_{2}^{11} \times\left\{2 \cos \left(11 \times 7.5^{\circ}-11 \times 1.875^{\circ}\right)\right\} \times\left\{2 \cos \left(11 \times 7.5^{\circ}\right)\right\}}{\left\{2 \cos \left(11 \times 7.5^{\circ}\right)\right\} \times\left\{2 \cos \left(11 \times 1.875^{\circ}\right)\right\}}=E_{2}^{11} \times 0.50
$$

$$
V_{I I}^{13}=\frac{E_{2}^{13} \times\left\{2 \cos \left(13 \times 7.5^{\circ}-13 \times 1.875^{\circ}\right)\right\} \times\left\{2 \cos \left(13 \times 7.5^{\circ}\right)\right\}}{\left\{2 \cos \left(13 \times 7.5^{\circ}\right)\right\} \times\left\{2 \cos \left(13 \times 1.875^{\circ}\right)\right\}}=E_{2}^{13} \times 0.3186 .
$$


switching pattern of Fig. 5(a), when compared to the respective harmonics in the previous switching pattern of Fig. 3(a).

In Fig. 5(a) it is shown that the switching vector pattern $I_{1}$ consists of two vector patterns separated by $30^{\circ}$. The corresponding switching vector pattern of inverter-2, shown in $I I_{1}$ of Fig. 5(a) consists of two vector patterns: one pattern lagging by $120^{\circ}$ from the lagging switching vector pattern of inverter- 1 and the other pattern leading by $120^{\circ}$ from the leading switching vector pattern of inverter-1. Hence, the different harmonic contents $(1,5,7,11,13,17,19,23,25$, etc.) of the pole voltage of inverter-1 and inverter- 2 for the new switching scheme (11th and 13th suppression) will have the same phase relationship as presented in Fig. 4 and Table I (inverter switching scheme of Fig. 3(a) with the magnitude of different components scaled down proportionally.

Hence, all $6 n \pm 1, n=1,3,5$, etc.-order harmonics are cancelled for the present scheme, with 11th- and 13th-order harmonic suppressed (11th is reduced by $50 \%$ and 13 th by $31.86 \%$ ) with the switching waveforms of Fig. 5(b). The combined effect of all the patterns with the phase voltage [i.e., $I_{1}, I I_{1}, I_{2}, I I_{2}$ of Fig. 5(a)] will give the fundamental, 11th harmonic, and 13th harmonic amplitudes equal to the value shown in (21)-(23), respectively. The resultant pole voltages for the two inverters are presented in Fig. 5(b).

The two inverters are operated with different dc-link voltages with the ratio $1: 0.366$. The fundamental component contribution from both the inverters toward the resultant machine phase voltage can be derived from Fig. 4(a). The fundamental voltage component magnitude contributed by inverter- 1 and inverter-2 are in the ratio $\left(\cos 45^{\circ} / \cos 15^{\circ}\right) 0.366$ [Fig. 4(a), (2), and (3)]. This will produce a resultant voltage space phasor magnitude of $1.223 \mathrm{~V}_{\mathrm{Dc}}$ (Fig. 2), when compared to a conventional two-level inverter with a voltage space phasor amplitude of $V_{D c}$. The inverter voltages for the two inverters (to produce a resultant space vector amplitude of $\mathrm{V}_{\mathrm{Dc}}$ ) of the present scheme are in the ratio (inverter-1 to inverter-2) $0.79: 0.21$. Current being the same, the voltage ratio of $0.79: 0.21$ also indicates the resultant power sharing between the inverters. Therefore, the additional low power inverter (inverter-2) of the present scheme can be realized with low-voltage devices such as MOSFETs. For the experimental verifications, a dc-link voltage of $200 \mathrm{~V}$ is used for the inverter- 1 and for the low-voltage inverter $(0.366 \times 200 \mathrm{~V})$ the appropriate ratio is achieved using a step-down transformer and then rectifying the mains for the dc link.

\section{EXPERIMENTAL RESULTS}

The above-described method is simulated and experimentally verified for a 1-hp induction motor with open-end winding. For the PWM operation, triangular wave is compared with appropriate modulating waves, which are generated from the corresponding pole voltages for the inverters. First, the $6 n \pm 1, n=1,3,5$, etc.-order harmonics elimination method with overmodulation. Switching vector patterns of Fig. 3(a) are experimentally verified [modulating waves derived from pole voltages of Fig. 3(b)] and the results are shown in Fig. 7. Fig. 7(a) shows the phase voltage of the motor. The phase voltage is analyzed for harmonic contents and its Fourier spectrum is given in Fig. 7(b). It can be noted that all the

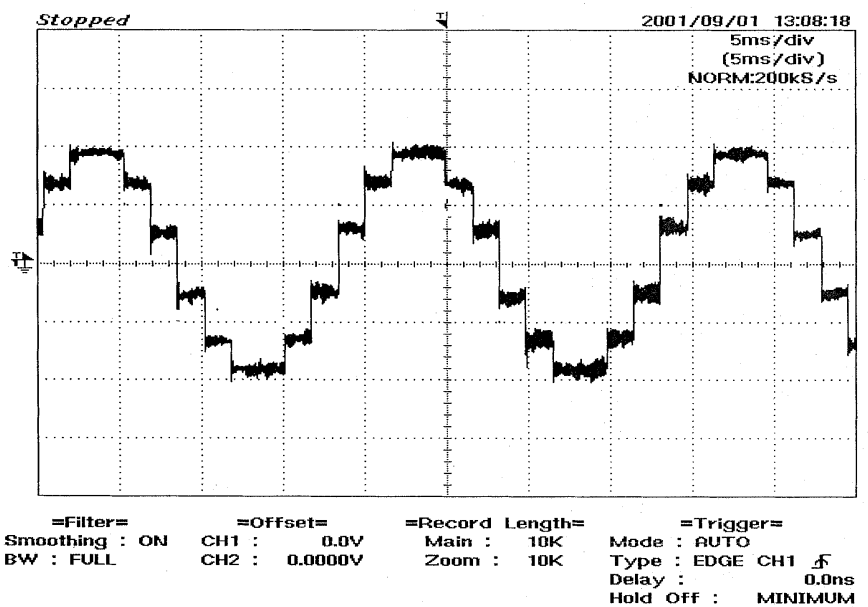

(a)

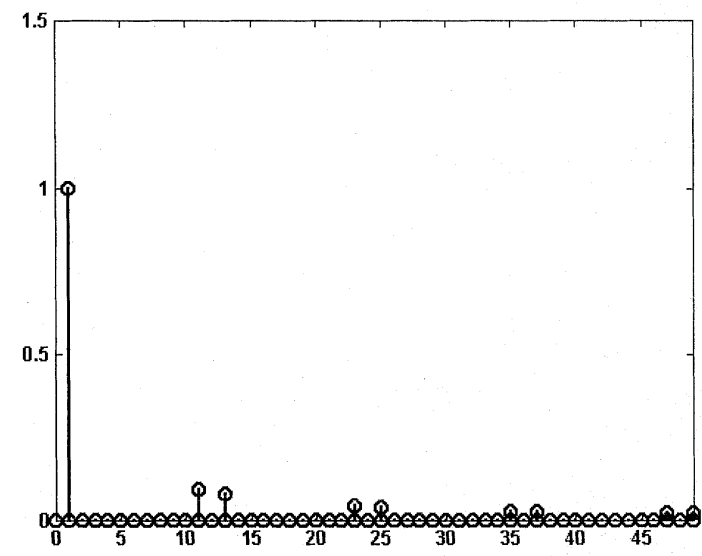

(b)

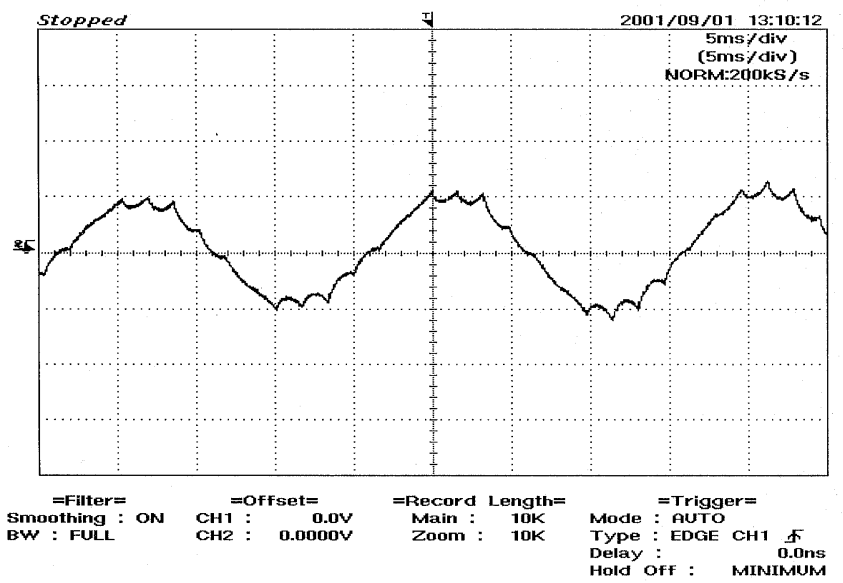

(c)

Fig. 7. Phase voltage-modulation index $=1.0$ (overmodulation). Without 11 th and 13th suppression. $Y$ axis: 75 v/div; $X$ axis: $5 \mathrm{~ms} /$ div. (b) Fourier spectrum of phase voltage-modulation index $=1.0$ (overmodulation). Without 11th and 13th suppression. (c) Phase current (no-load operation)modulation index $=1$. Without 11th and 13th suppression. $Y$ axis: $1 \mathrm{~A} /$ div; $X$ axis: $5 \mathrm{~ms} / \mathrm{div}$.

$6 n \pm 1, n=1,3,5$, etc.-order harmonics are absent in the Fourier spectrum, with 11th and 13th as the next higher order harmonics in the motor phase voltage. Fig. 7(c) shows the motor phase current waveform under no-load operation. 


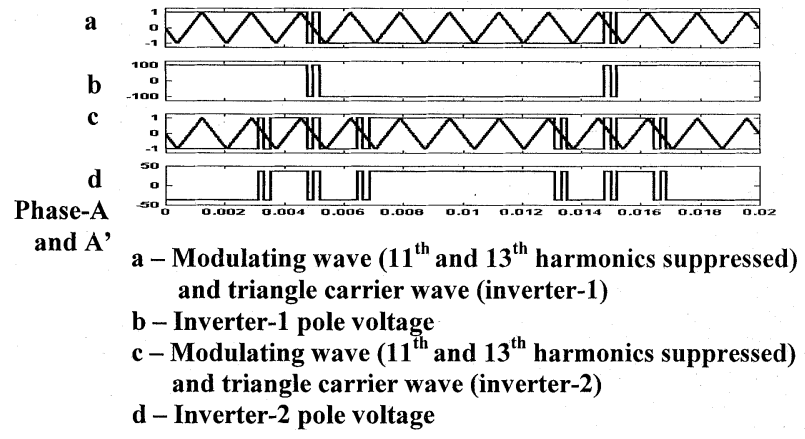

(a)

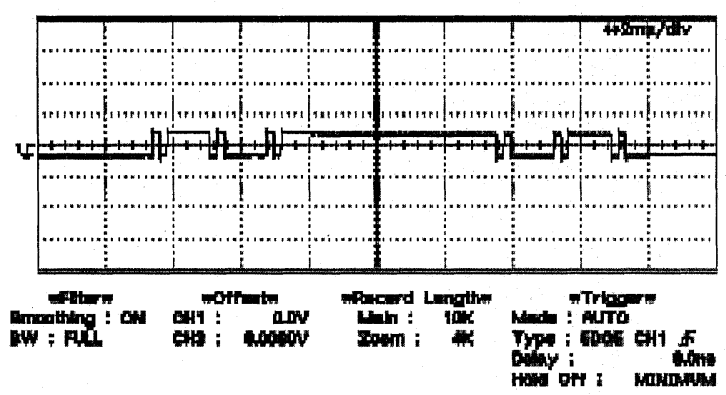

(c)

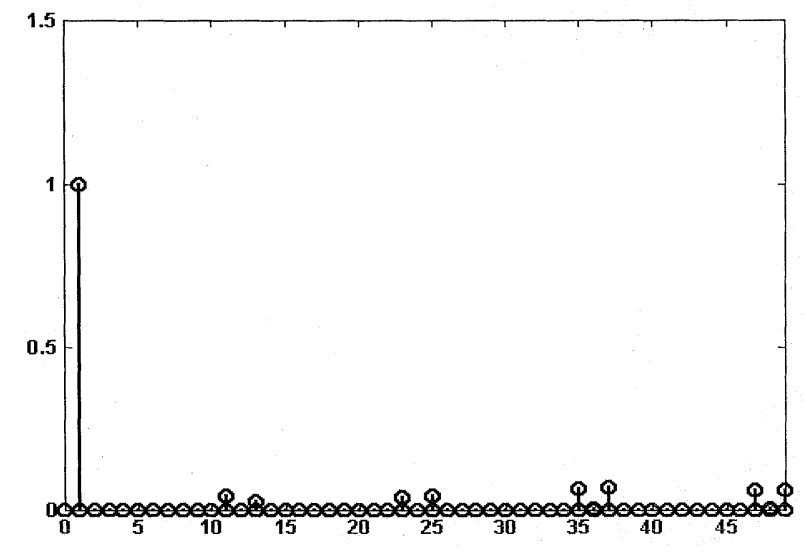

(e)

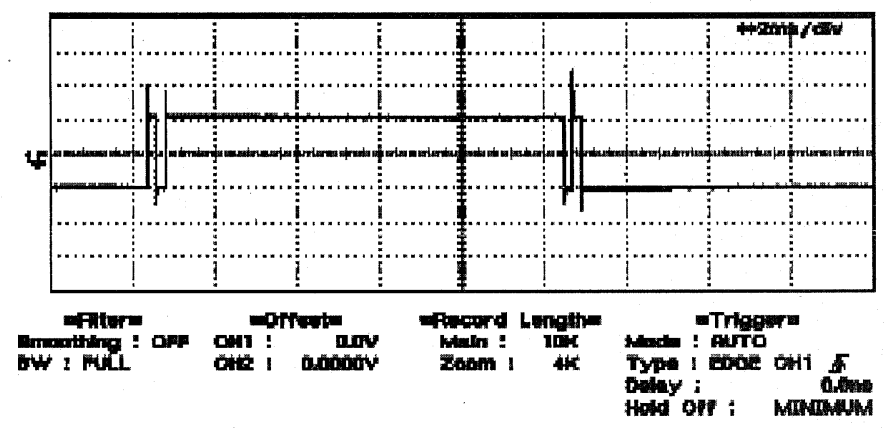

(b)

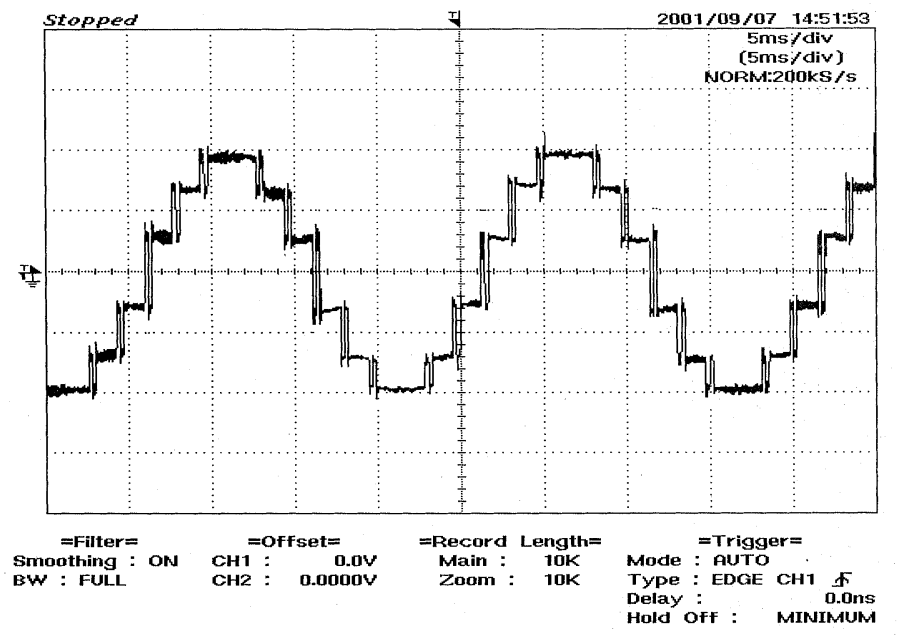

(d)

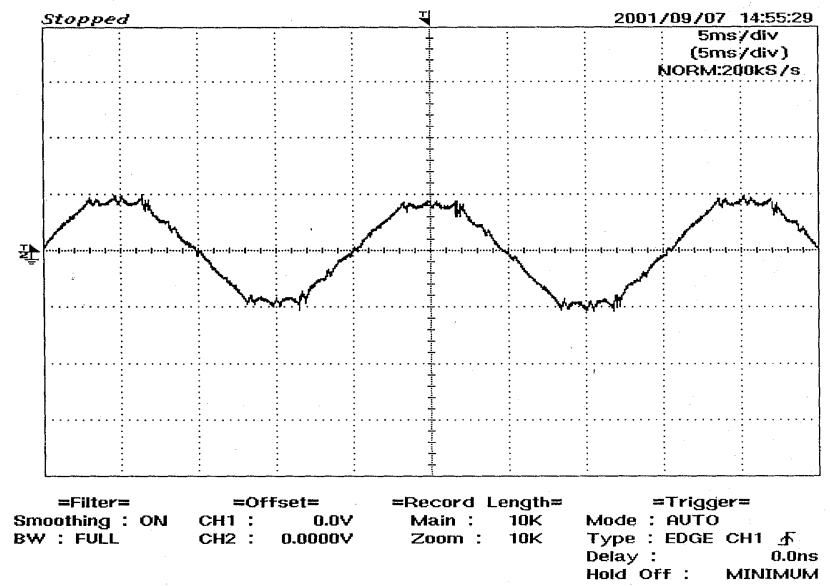

(f)

Fig. 8. (a) Modulating wave and triangular carrier wave (overmodulation) $f c / f=12$. (b) Pole voltage of inverter-1 (overmodulation). $Y$ axis: 100 V/div; $X$ axis: $5 \mathrm{~ms} / \mathrm{div}$ (experimental results). (c) Pole voltage of inverter-2 (overmodulation). $Y$ axis: $100 \mathrm{~V} / \mathrm{div}$; $X$ axis: 5 ms/div (experimental results). (d) Modulation index $=1.0$ Overmodulation. Phase voltage. With 11th and 13th suppressed. $Y$ axis: $75 \mathrm{~V} / \mathrm{div} ; X$ axis: $5 \mathrm{~ms} / \mathrm{div}$. (e) Modulation index $=1.0$. Overmodulation. Fourier spectrum. With 11th and 13th suppressed. (f) Modulation index $=1.0$. Overmodulation. Phase current. With 11th and 13th suppressed. $Y$ axis: $1 \mathrm{~A} /$ div; $X$ axis: $5 \mathrm{~ms} / \mathrm{div}$.

Then, the 11th- and 13th-order harmonic suppression with $6 n \pm 1, n=1,3,5$, etc.-order harmonics elimination method (modulating waves derived from pole voltages of Fig. 5(b) is experimentally verified. Fig. 8(a) shows the simulated pole voltage waveforms and triangle waveforms used for PWM operation of both the inverters (inverter- 1 and inverter-2) in the case of overmodulation (amplitude of the modulating wave is greater than the triangular carrier wave amplitude) for phase $A$ phase- $A^{\prime}$. The corresponding experimental waveforms of pole voltage of both inverters and the motor phase voltage are shown in Fig. 8(b)-(d), respectively. The Fourier spectrum [Fig. 8(e)] shows the absence of $6 n \pm 1, n=1,3,5$, etc.-order harmonics and the 11th- and 13th-order harmonics are suppressed compared to the same given in Fig. 7(b). The phase 
current waveform (under no-load operation) obtained from experiment is shown in Fig. 8(f).

To operate the IM in the entire speed range (from zero to rated speed), it is required to vary the input voltage with frequency. Therefore, a PWM scheme in which a triangular wave is compared with the pole voltages of Fig. 5(b) as the modulating wave is used for the operation of the inverters under variable modulation indexes.

In order to retain the elimination of all the $6 n \pm 1, n=1,3,5$, etc.-order harmonics in the harmonic spectrum a triangle carrier frequency of $6 n, n=1,2,3$, etc., is required [11]. In the case of a modulation index less than one, if we compare the modulating wave with a triangle carrier with six times the frequency $(f c=6 f)$, then the effect of 11th- and 13th-order harmonic suppression is nullified because of the additional 11thand 13th-order harmonic generation $(2 f c \pm f)$ due to the triangle carrier wave [11]. Hence, a triangle frequency of 12 times the fundamental is used so that the next higher order harmonic contributed by the triangular carrier are 23rd and 25th [11]. Fig. 9(a) shows the phase voltage waveform obtained from experiment for the modulation index 0.45 . Its harmonic content is shown in Fig. 9(b). It can be noted that the 11th and 13th harmonics are suppressed and the next higher harmonic due to triangle carrier are at $23 \mathrm{rd}$ and 25 th order. There is also no presence of any $6 n \pm 1, n=1,3,5$, etc.-order harmonic in the harmonic spectrum [Fig. 9(b)]. Fig. 9(b) also shows that a slight increase in 23rd- and 25th-order harmonics compared to that of square-wave operation of Fig. 8(c). This is because of the PWM action where additional harmonics of $(2 f c \pm f)$ are generated due to the PWM action [11]. The phase current waveform of the experiment is shown in Fig. 9(c). Another set of experimental results is given in Fig. 10 for a modulation index of 0.9 $(6 n \pm 1, n=1,3,5$, etc., are completely eliminated with 11 thand 13th-order suppression).

Therefore, with the proposed PWM scheme all the $6 n \pm 1$, $n=1,3,5$, etc.-order harmonics can be eliminated along with suppression of 11th- and 13th-order harmonics for the entire modulation range. With the square wave with symmetric notches type modulating waves for both inverters a smooth transition from PWM mode to overmodulation mode is also possible for the present scheme.

In the conventional sine-triangle PWM technique, a very high-frequency carrier wave is needed to suppress the low-frequency harmonic amplitudes. This can also increase the inverter switching losess. Moreover, to fully utilize the inverter dc-link capability, the PWM scheme has to go through the nonlinear overmodulation regions. Therefore, extra complicated computations and lookup tables are needed for linearizing the overmodulation regions. In the present scheme, the triangular carrier wave is compared with dc levels of the square waves (with additional notches to suppress the 11th and 13th harmonics), and the height of this dc level can be adjusted (compared to the fixed triangular amplitude) in proportion to the modulation indexes. At higher speed range (higher modulation index) by increasing the square-wave amplitude the output voltage level can be increased proportionally, with smooth transition to the six-step mode in which the de levels are just above the triangular amplitude. At the same time

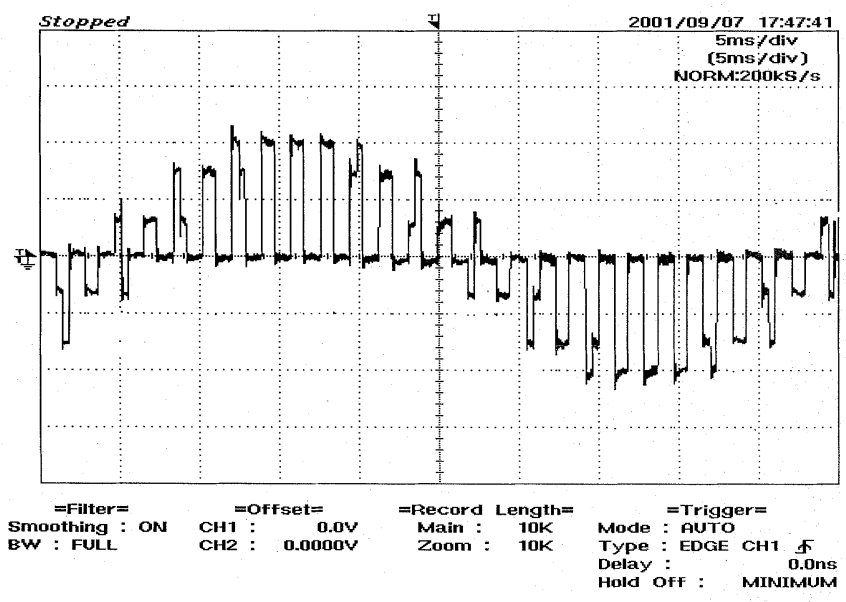

(a)

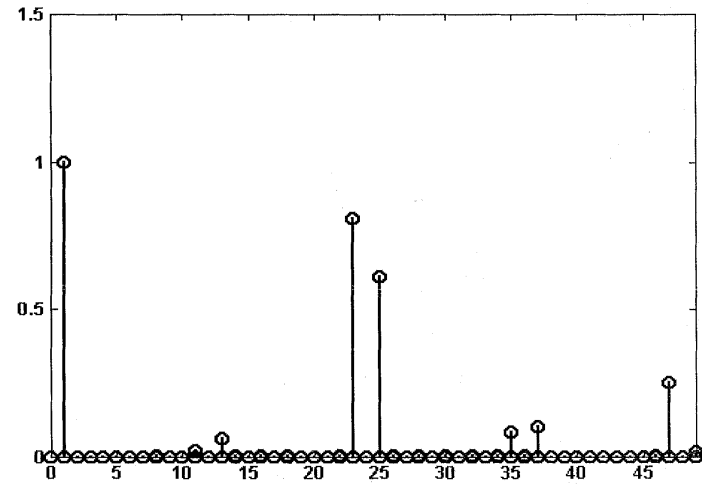

(b)

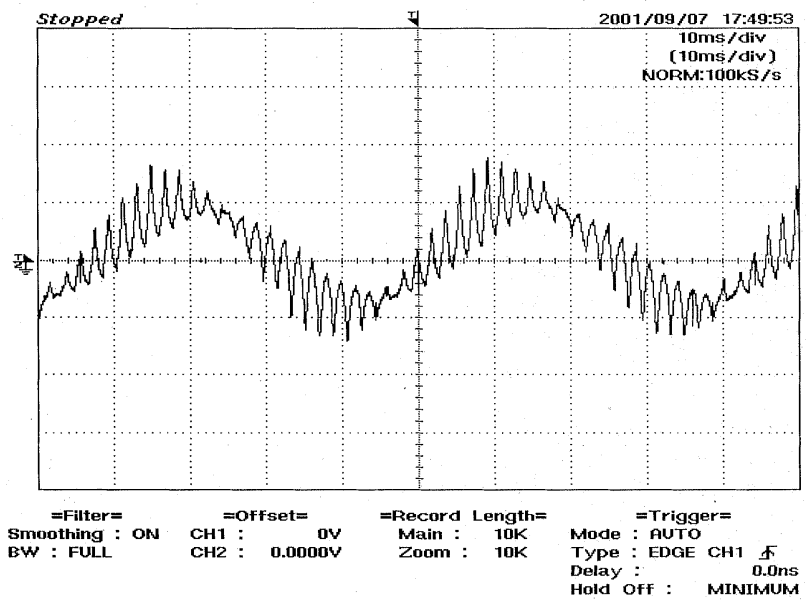

(c)

Fig. 9. (a) Modulation index $=0.45$. Phase voltage. $f c=12 f$. With 11 th and 13th suppressed. $Y$ axis: $75 \mathrm{~V} / \mathrm{div} ; X$ axis: $5 \mathrm{~ms} /$ div. (b) Modulation index $=0.45$. Fourier spectrum. $f c=12 f$. With 11th and 13th suppressed. (c) Modulation index $=0.45$. Phase current. $f c=12 f$. With 11 th and 13th suppressed. $Y$ axis: $1 \mathrm{~A} / \mathrm{div} ; X$ axis: $10 \mathrm{~ms} / \mathrm{div}$.

high-frequency carrier waves are not needed, in the proposed scheme, for the low-frequency harmonic amplitudes reduction, when compared to a sine-triangle comparison technique. The present PWM scheme with open-end winding drive is analyzed for its harmonic contents in the entire speed range for different modulation indices. $(f c / f=12,24,48)$. The amplitude of 


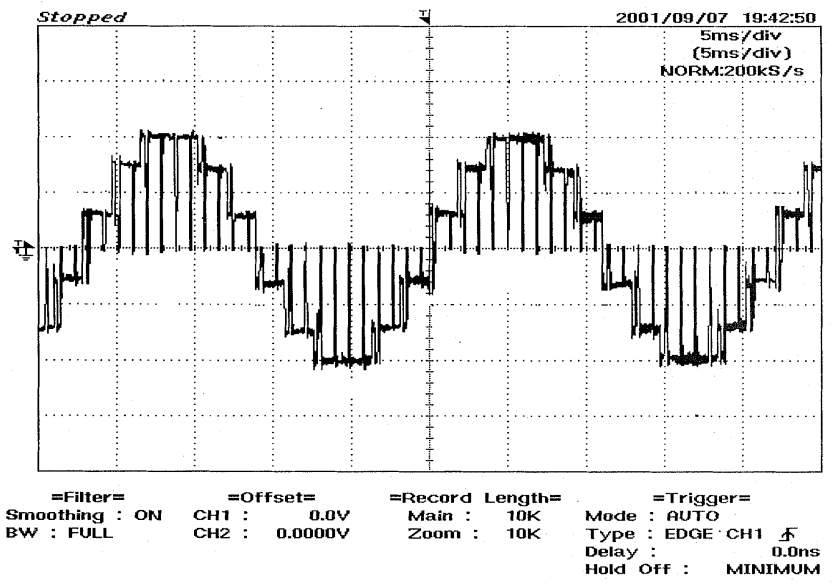

(a)

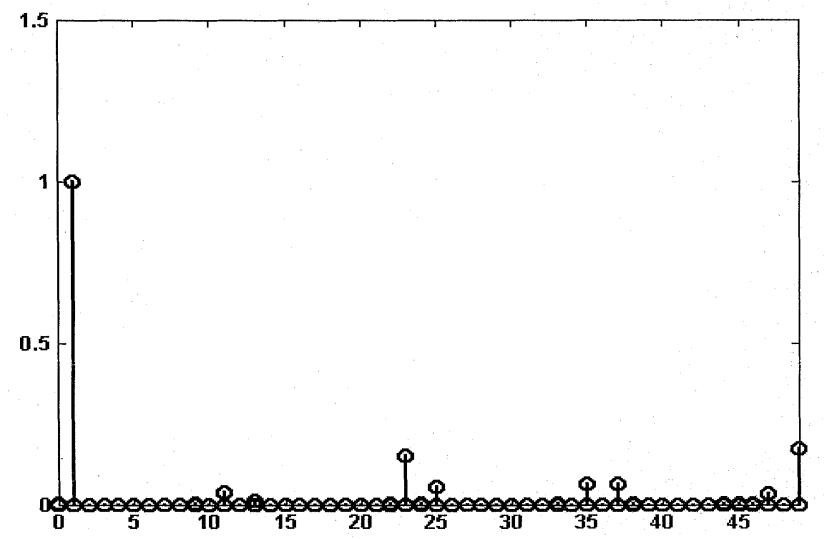

(b)

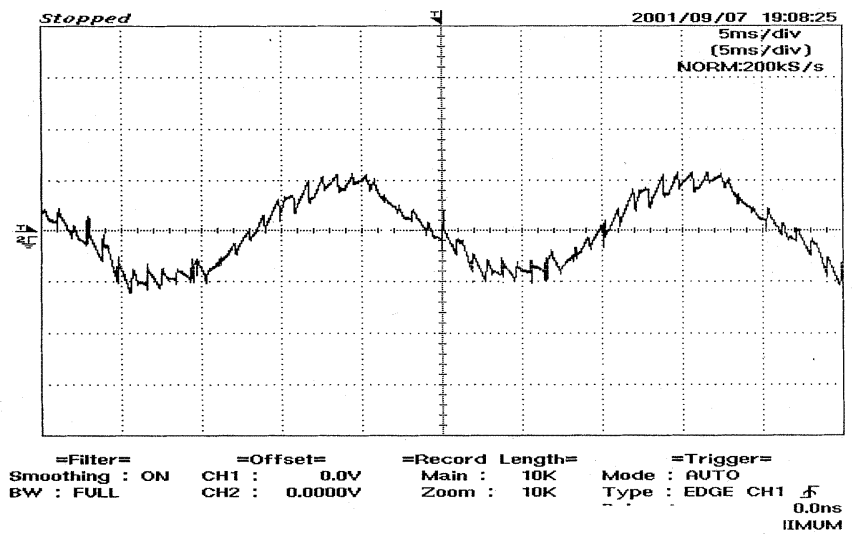

(c)

Fig. 10. (a) Modulation index $=0.9$. Phase voltage. $f c=12 f$. With 11th and 13th suppressed. $Y$ axis: $75 \mathrm{~V} / \mathrm{div} ; X$ axis: $5 \mathrm{~ms} / \mathrm{div}$. (b) Modulation index $=0.9$. Fourier spectrum. $f c=12 f$. With 11th and 13th suppressed. (c) Modulation index $=0.9$. Phase current. $f c=12 f$. With 11th and 13th suppressed. $Y$ axis: $1 \mathrm{~A} /$ div; $X$ axis: $5 \mathrm{~ms} /$ div.

low-order harmonics and fundamental for the entire modulation range $(f c / f=12)$ is computed and the relative harmonic amplitudes with respect to fundamental are shown in Fig. 11(a). It can be noted that all the $6 n \pm 1, n=1,3,5$, etc.-order harmonics are absent in the entire speed range, with $f c / f$ equal to 12 the next high-order harmonics are at 23rd and 25th times the frequency of the fundamental in Fig. 11(b). With $f c / f$ equal

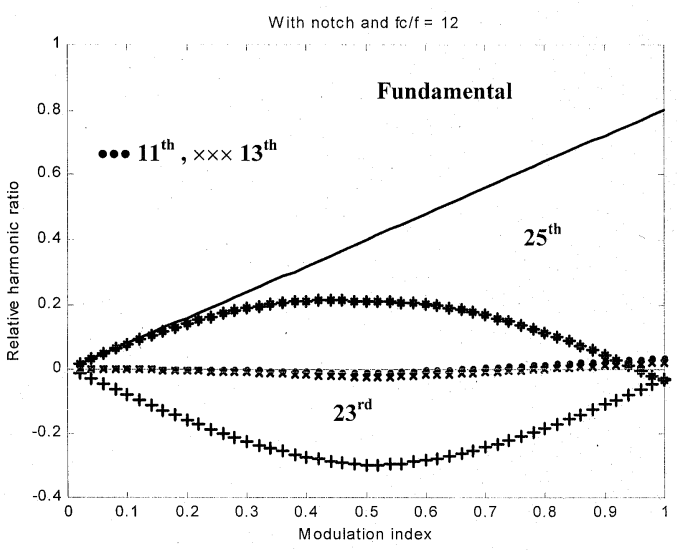

(a)

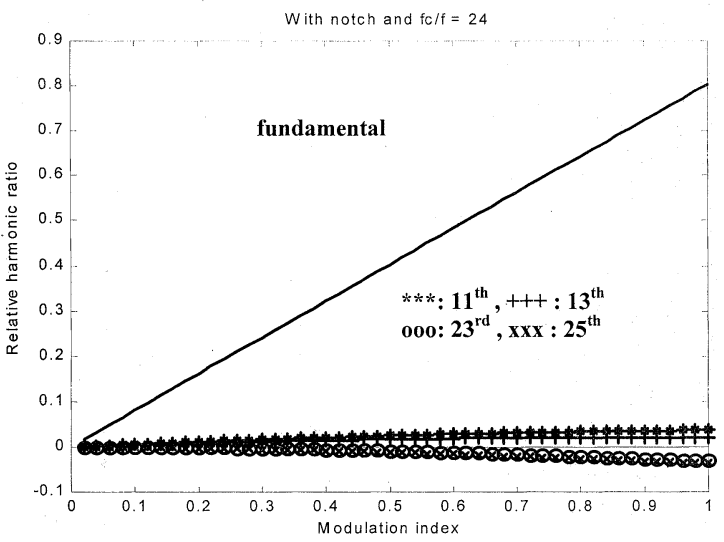

(b)

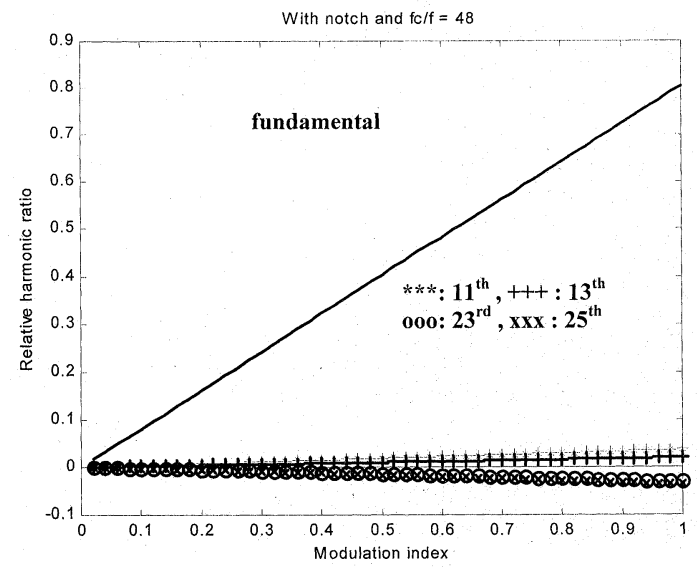

(c)

Fig. 11. (a) Relative harmonic ratio versus modulation index. $\mathbf{f c} / \mathbf{f}=12$. (b) Relative harmonic ratio versus modulation index. $\mathbf{f c} / \mathbf{f}=24$. (c) Relative harmonic ratio versus modulation index. $\mathbf{f c} / \mathbf{f}=48$.

to 24 the high-amplitude harmonics will be shifted to 47 th and 49th times the frequency of the fundamental and at the same time eliminate all the $6 n \pm 1, n=1,3,5$, etc.-order harmonics. In case of $f c / f$ equal to 48 , the amplitude of fundamental and harmonics for the entire speed range for the high-amplitude loworder harmonics are also computed and are shown in Fig. 11(c). Here, the high amplitude will be shifted to 95th and 97th times the frequency of the fundamental $(2 f c \pm f)$ [11]. Therefore, from Fig. 11 it can be noted that the fundamental varies linearly 
for the entire modulation range. Also, by properly choosing $f c / f(12,24,48)$ at different speed ranges $(0-50 \mathrm{~Hz})$ the inverter switching frequency can be kept within $600 \mathrm{~Hz}$ and as well the harmonic current amplitude can be controlled within an acceptable limit for variable-speed applications.

\section{CONCLUSION}

A harmonic elimination $(6 n \pm 1, n=1,3,5 \ldots)$ and suppression scheme (11th and 13th) with $v / f$ control was proposed for an open-end winding IM drive. The scheme is experimentally verified for a 1-hp IM drive. For the present scheme the neutral of a normal induction motor is opened (open-end winding IM) and is fed from both sides using two two-level inverters. The salient features of the proposed scheme are as follows.

- Two inverters with asymmetrical dc-link voltage of ratio $1: 0.366$ are needed.

- For the high-voltage inverter a square-wave modulating wave with two symmetric notches per half cycle is used for PWM control and for the other low dc-link voltage inverter a square wave with four symmetric notches per half cycle is used as a modulating wave for PWM control.

- A carrier wave of frequency 12 times the frequency of the modulating wave is used experimentally for $v / f$ control for the entire speed range.

- All the $6 n \pm 1, n=1,3,5$,etc.-order harmonics are eliminated from the motor phase voltage in the entire speed range and 11th- and 13t-order harmonics are suppressed.

- A smooth and linear transition to the overmodulation region is possible for the present drive.

- The relative harmonic amplitudes with respect to fundamental are computed for the entire speed range for frequency-modulation ratios of $(f c / f) 12,24$, and 48 and the results are presented.

- By properly choosing the frequency modulation ratio (12, 24,48 ) at different speed ranges, theswitching frequency of both inverters can be controlled within $600 \mathrm{~Hz}$.

- Since two inverters with asymmetric dc-link voltage are needed, transformer-isolated dc-link power supplies are needed for the scheme, which will also ensure the isolation of triplen harmonic currents from the motor phase.

\section{APPENDIX}

Motor Parameters: 1-hp Three-Phase IM-Four Poles

$$
\begin{aligned}
R_{s} & =2.08 \Omega \\
R_{r} & =4.19 \Omega \\
L_{s} & =0.28 \mathrm{H} \\
L_{r} & =0.28 \mathrm{H} \\
M & =0.272 \mathrm{H} .
\end{aligned}
$$

\section{REFERENCES}

[1] A. Nabae, I. Takahasi, and H. Akasi, "A neutral-point clamped PWM inverter," in Conf. Rec. IEEE-IAS Annu. Meeting, 1980, pp. 530-536.

[2] P. M. Bhagwat and V. R. Stefanovic, "Generalized structure of a multilevel PWM inverter," IEEE Trans. Ind. Applicat., vol. IA-19, pp. 1057-1069, Nov./Dec. 1983.

[3] J.-S. Lai and F. Z. Peng, "Multilevel converters-A new breed of power converters," IEEE Trans. Ind. Applicat., vol. 32, no. 3, pp. 509-517, May/June 1996.

[4] H. Stemmler and P. Guggenbach, "Configuration of high power voltage source inverter drives," in Proc. EPE Conf., vol. 5, 1993, pp. 742-747.
[5] E. G. Shivakumar, K. Gopakumar, S. K. Sinha, A. Pittet, and V. T. Rangathan, "Space vector PWM control of dualinverter fed open-End winding induction motor drive," in Proc. IEEE APEC, 2001, pp. 399-405.

[6] K. Gopakumar and R.-G. Hie, "Configuration of high power VSI drives for traction applications using multilevelinverters and multiphase induction motors," in Proc. KIEE Fall Conf., 1997, pp. 500-504.

[7] E. G. Shivakumar, V. T. Somasekhar, K. K. Mohapatra, K. Gopakumar, L. Umanand, and S. K. Sinha, "A multi levelspace phasor based PWM strategy for an open-end winding induction motor drive using two inverters with differentDC-link voltages," in Proc. 4th IEEE Int. Conf. Power Electronics and Drive Systems, 2001, pp. 169-175.

[8] H. S. Patel and R. G. Hoft, "Generalized techniques of harmonic elimination and voltage control in thyristor inverters," IEEE Trans. Ind. Applicat., vol. IA-9, pp. 310-317, May/June 1973.

[9] K. Thorborg and A. Nystrom, "Stair case PWM: An uncomplicated and efficient modulation technique for AC motordrives," IEEE Trans. Power Electron., vol. 3, pp. 391-397, Oct. 1988.

[10] Y. Zhao and T. A. Lipo, "Space vector PWM control of dual three phase induction machine using vector spacedecomposition," in Conf. Rec. IEEE-IAS Annu. Meeting, 1994, pp. 742-748.

[11] N. Mohan, T. R. Undeland, and W. P. Robbins, Power Electronics Converters, Applications, and Design. New York: Wiley, 1989.

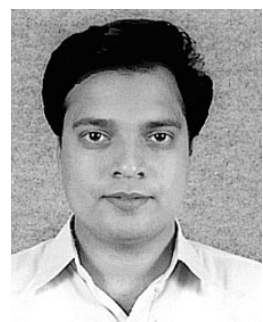

Krushna K. Mohapatra (S'02) received the B.E. degree from the Regional Engineering College, Rourkela, India, in 1993, and the M.Tech degree from the Indian Institute of Technology, Kharagpur, India, in 1996, both in electrical engineering. He is currently working toward the Doctoral degree in the Centre for Electronics design and Technology, Indian Institute of Science, Bangalore, India.

From 1995 to 2000, he was a Design and Development Engineer with National Radio and Electronics Company Ltd. His research interests are in the areas of power converters, PWM strategies, and motor drives.

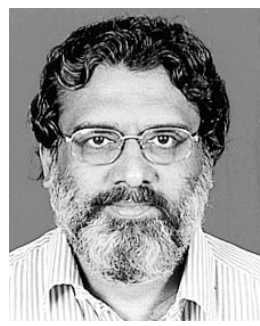

K. Gopakumar (M'94-SM'96) received the B.E., M.Sc. (Engg.), and Ph.D. degrees from the Indian Institute of Science, Bangalore, India, in 1980, 1984, and 1994, respectively.

$\mathrm{He}$ was with the Indian Space Research Organization from 1984 to 1987 . He is currently an Assistant Professor in the Centre for Electronics Design and Technology, Indian Institute of Science, Bangalore, India. His fields of interest are power converters, PWM techniques, and ac drives.

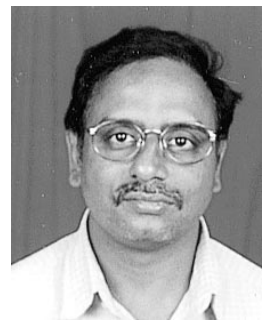

V. T. Somasekha (S'00) received the B.Tech. degree in electrical engineering from the Regional Engineering College (REC), Warangal, India, in 1987, and the M.Tech. degree with a specialization in power electronics from the Indian Institute of Technology, Bombay, India, in 1990. He is currently a Research Student in the Centre for Electronics Design and Technology, Indian Institute of Science, Bangalore, India, working toward the Doctoral degree.

$\mathrm{He}$ was an R\&D Engineer with M/S Perpetual Power Technologies, Bangalore, India, and Kirloskar Electric Company Ltd., Mysore, India. In 1993, he joined the Faculty of Electrical Engineering, REC, Warangal, as a Lecturer.

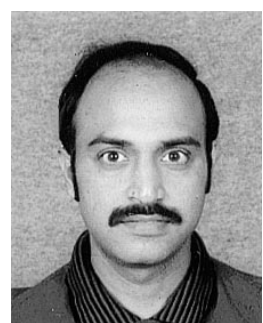

L. Umanand received the B.E. degree from Bangalore Univesity, Bangalore, India, in 1987, and the M.Tech. and Ph.D degrees from the Centre for Electronics Design and Technology, Indian Institute of Science, Bangalore, India, in 1989 and 1996, respectively.

He has been a faculty member of the Centre for Electronics Design and Technology, Indian Institute of Science, Bangalore, India, since 1989. His fields of interest are power conversion, electric vehicles, and photovoltaic systems. 